\title{
Concurrent Nimotuzumab with Radiation Therapy in Locally Advanced Cancers of Oropharynx and Hypopharynx: A Review of 6 Cases
}

\author{
B. Ravi Shankar'1, Poojar Kiran², B. V. Madhavi'3 , E. Vijay ${ }^{4}$ \\ ${ }^{1}$ Department of Radiotherapy, Andhra Medical College, Vishakhapatnam, India \\ ${ }^{2} \mathrm{VIMS}$, Bangalore, India \\ ${ }^{3}$ Department of Pathology, Government Medical College, Ananthapur, India \\ ${ }^{4} \mathrm{MSL}$, Hyderabad, India \\ Email: Ravi bellala@yahoo.co.in
}

Received 29 January 2015; accepted 29 April 2015; published 30 April 2015

Copyright (C) 2015 by authors and Scientific Research Publishing Inc.

This work is licensed under the Creative Commons Attribution International License (CC BY). http://creativecommons.org/licenses/by/4.0/

(c) (i) Open Access

\section{Abstract}

Background: The prevalence of head and neck cancers in the world is around $\mathbf{5 7 \%}$ and predominantly occurs in Asian countries. It accounts for $30 \%$ of all cancers in India. The cure rate of locally advanced squamous cell carcinoma of the head and neck (SCCHN) has only $30 \%-60 \%$ even after combined therapeutic approaches. Epidermal Growth Factor Receptor (EGFR) antagonists are the most researched targets in the management of head and neck cancers. Claims at superior tumor control and additional survival benefit without any added toxicity make it an attractive option. With this case series we intend to see how nimotuzumab, a humanized monoclonal antibody, fares in difficult cases of head and neck cancers. Case Description: In this case series, total six patients of locally advanced cancer of head and neck region were treated weekly using cisplatin and nimotuzumab concurrently with radiation therapy (RT) for 6 - 7 weeks. Depending upon the disease stage as well as the general condition of the patient, different dose cycles and radiation doses were tailored. Patients were monitored for regular physical examinations and hematological tests followed by pre and post treatment computed tomography (CT) scans, Fludeoxyglucose positive emission tomography (FDG PET-CT) scans, and histopathology. All patients were assessed for toxicities and managed consequently. After completion of radiation and follow-up, 6 weeks later post treatment CT scans were carried out. Conclusion: This case series shows that combination of chemoradiation with nimotuzumab achieved good response rates with no evidence of residual disease/disease progression on follow-up. The patients' tolerability with combination therapy was good and toxicity was acceptable. Nimotuzumab was found beneficial in combination with chemoradiation for locally advanced head and neck cancers. 


\section{Keywords}

\section{Squamous Cell Carcinoma of the Head and Neck (SCCHN), Nimotuzumab, Epidermal Growth Factor Receptor (EGFR), Chemoradiation Therapy}

\section{Introduction}

Globally, 57.5\% of head and neck cancers that occur in Asia and India constitute a majority of these cases. In India, $30 \%$ of all cancers belong to head and neck region. Up to $60 \%-80 \%$ of these are of advanced stage [1]. Locally advanced squamous cell carcinoma of the head and neck (SCCHN) has cure rate of only $30 \%-60 \%$, even with combined therapeutic approaches [2]. This implicates the need for more effective therapies [3] [4] that can improve response rates and survival in locally advanced SCCHN.

Epidermal Growth Factor Receptor (EGFR) is becoming one of the most extensively investigated targets in anticancer therapies. It is due to the fact that elevated levels of EGFR are responsible for malignant transformation of neoplastic cells observed in several types of cancers. Overexpression of EGFR is associated with high recurrence rate and less response to conventional treatment modalities. SCCHN is one of the widely studied cancer types for EGFR expression and now drugs are available for targeting these receptors [5]. Cetuximab is the first anti-EGFR agent approved for treatment in head and neck cancers [6]. Due to limitations of its toxicity profile in combination with radiation, nimotuzumab is being investigated as a safer alternative with better efficacy and toxicity profile [5] [6].

Here we discuss 6 cases of locally advanced cancer of head and neck region that were treated using weekly cisplatin and nimotuzumab concurrently with radiation therapy (RT) for 6 - 7 weeks. Different dose cycles and radiation doses were used as per the requirement of the disease stage and the general condition of the patient.

Patients underwent regular physical examinations, haematological tests, pre and post treatment computed tomography (CT) scans, Fludeoxyglucose positive emission tomography (FDG PET-CT) scans (as indicated) and histopathology in all of them. Patients were evaluated weekly for toxicities and managed accordingly. Post treatment CT scans were performed 6 weeks after the completion of radiation and follow up.

\section{Case Reports}

\subsection{Case 1}

A 54-year-old gentleman, with a history of at least 20 pack years cigarette smoking, presented with progressive dysphagia and swelling in right side of neck of 2 months duration. On evaluation, there was a right level III cervical lymph node measuring $5 \mathrm{~cm} \times 4 \mathrm{~cm}$. Nasopharyngolaryngoscopy showed a growth $4 \mathrm{~cm} \times 3 \mathrm{~cm}$ involving the right aryepiglottic fold, extending on to thevallecula. Biopsy from the growth was reported as squamous cell carcinoma. The patient was started on weekly cisplatin $40 \mathrm{mg} / \mathrm{m}^{2}$ and nimotuzumab $200 \mathrm{mg}$ with radiation therapy. He received 3D conformal radiotherapy on linear accelerator with a daily dose of $200 \mathrm{cGy}, 5$ days/wk to a total dose of $6600 \mathrm{cGy} / 33$ fractions and 6 cycles of chemo-immunotherapy. On completion of treatment, there was appreciable reduction in the size of the lymph node but it was still clinically palpable having a mean size of $1 \mathrm{~cm} \times 1.5 \mathrm{~cm}$. A PET was done to evaluate the functional uptake in the cervical lymph node. PET CT revealed mild uptake in the cervical lymph node. To address the residual disease in neck, functional neck dissection was done and histopathology of the dissected nodes showed no viable tumor deposits, suggesting a complete pathological response.

The patient was followed up for 24 months; CT scan displayed a good response to combination of radiation with cisplatin and nimotuzumab (Figure 1).

\subsection{Case 2}

A 50-year-old gentleman, chronic smoker for 25 years, presented with a painless swelling in the right upper neck for one month duration. On examination there was a firm, indurated, irregular non-tender mass of $5 \mathrm{~cm} \times 4 \mathrm{~cm} \times$ 
$21^{\text {st }}$ Feb 2011

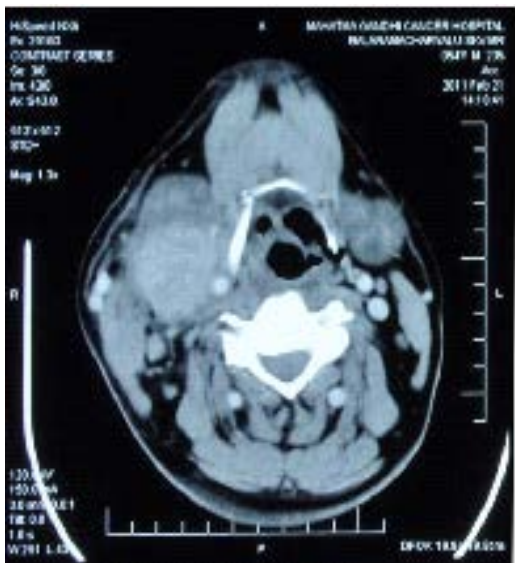

(a) $5^{\text {th }}$ July 2011

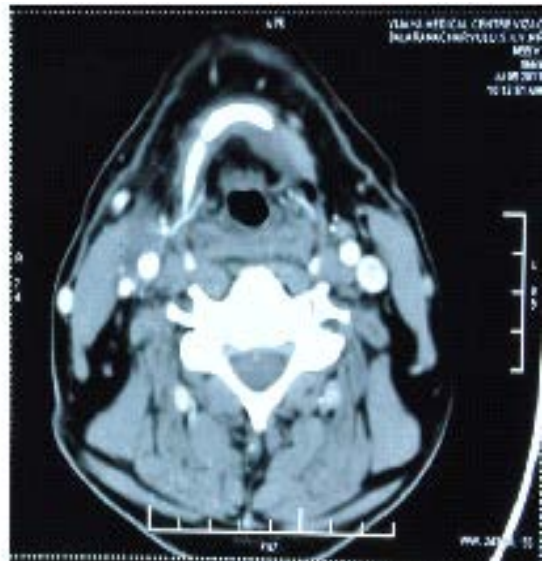

(b)

Figure 1. (a) Pretreatment-CECT of neck showing right upper cervical lymph node measuring $5 \mathrm{~cm} \times 4 \mathrm{~cm}$ with central necrosis; (b) Post treatment-CECT of neck showing very minimal enhancing lesion in the right side of neck. Post CT \& RT, the residual disease measures $1 \mathrm{~cm} \times 0.7 \mathrm{~cm}$.

$3 \mathrm{~cm}$ in the right upper neck level IIB. Another swelling of size $4 \mathrm{~cm} \times 2 \mathrm{~cm}$ was present on the right side of neck in the submandibular region of level IB. Upper gastro intestinal endoscopy and CT scan revealed an ulceroproliferative irregular growth in the right posterior 1/3rd of tongue. It was extending from the right posterolateral base of the tongue and to the vallecula. Lesion was measuring $4 \mathrm{~cm} \times 3 \mathrm{~cm}$. Biopsy was taken from growth on posterior one third of tongue. It revealed squamous cell carcinoma grade 2 . He was diagnosed to have carcinoma oropharynx T4aN2bM0.

He was started on weekly cisplatin $40 \mathrm{mg} / \mathrm{m}^{2}$ and nimotuzumab $200 \mathrm{mg}$ for a total of 6 cycles. Radiation was delivered to a total dose of $60 \mathrm{~Gy} / 30$ fractions/ 6 weeks through parallel-opposed portals on Co-60. At first follow up, clinical examination did not revealed any lesion and CT scan showed small residual induration measuring $1 \mathrm{~cm} \times 0.8 \mathrm{~cm}$ on the right base of the tongue which depicted considerable decrease in the size of the lesion (Figure 2). Biopsy of this lesion was negative for malignancy. Patient has been on follow-up for 6 years and is doing well with good general condition. He has reported no adverse reactions related to nimotuzumab.

\subsection{Case 3}

A 68-year-old man with significant smoking history presented with complaints of dysphagia for 3 months. He was a known diabetic and had a past history of cerebrovascular disease. He was evaluated for his complaints and a CT scan revealed a mass measuring $3.6 \mathrm{~cm} \times 2.5 \mathrm{~cm} \times 2.0 \mathrm{~cm}$ on the right lateral oropharyngeal wall involving the right tonsil and cervical lymphadenopathy involving submandibular nodes. Biopsy of the lesion from the Tonsil was reported as poorly differentiated squamous cell carcinoma. The patient was started on weekly cisplatin $30 \mathrm{mg} / \mathrm{m}^{2}$ (dose of cisplatin reduced due to co-morbid cerebrovascular accident) and nimotuzumab $200 \mathrm{mg}$ for a total of 6 cycles. Radiation was delivered by IMRT technique to a total dose of $66 \mathrm{~Gy} / 33$ fractions/61/2 weeks. Follow up CT scan, after CT-RT showed no residual mass in the tonsillar area and reduction in the size of submandibular lymph node to $0.5 \times 0.5 \mathrm{~cm}$ with tiny cervical lymphnodes (Figure 3 ). The treatment regimen was well tolerated by the patient. Recent follow-up did not show any evidence of residual tumor clinically or radiologically and endoscopically.

\subsection{Case 4}

A 62-year-old gentleman, chronic smoker for 20 years with occasional alcohol intake, presented with complaints of progressively increasing swelling on the right side of neck of 5 months duration. On physical examination of neck there was a large lymph node mass measuring $7 \mathrm{~cm} \times 6 \mathrm{~cm}$ on the right side of the neck. It was hard in consistency and fixed to the underlying neck strap muscles. No visible or palpable primary lesion was detected 


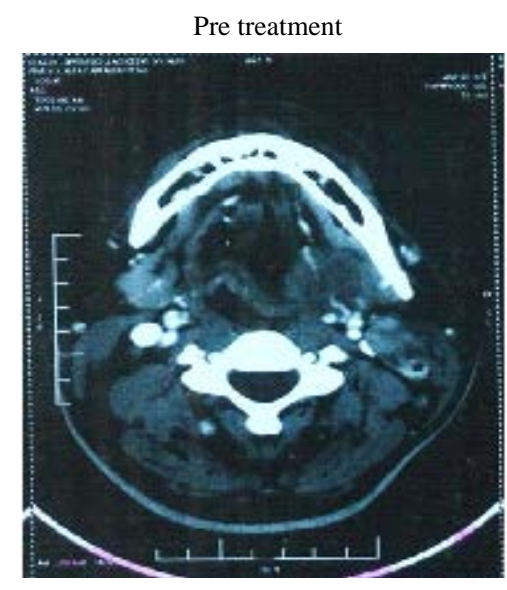

(a)
Post 1 year after treatment

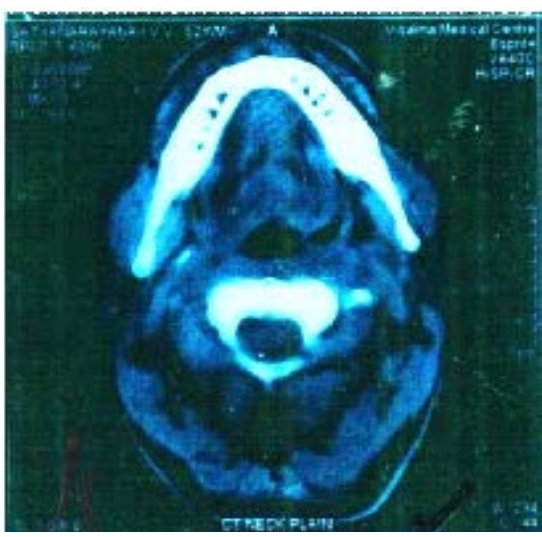

(b)

Figure 2. (a) Pretreatment-CECT of neck showing an oropharyngeal growth involving the right base of tongue; (b) Post treatment-CECT of neck showing small residual thickness in the right oropharyngeal region.

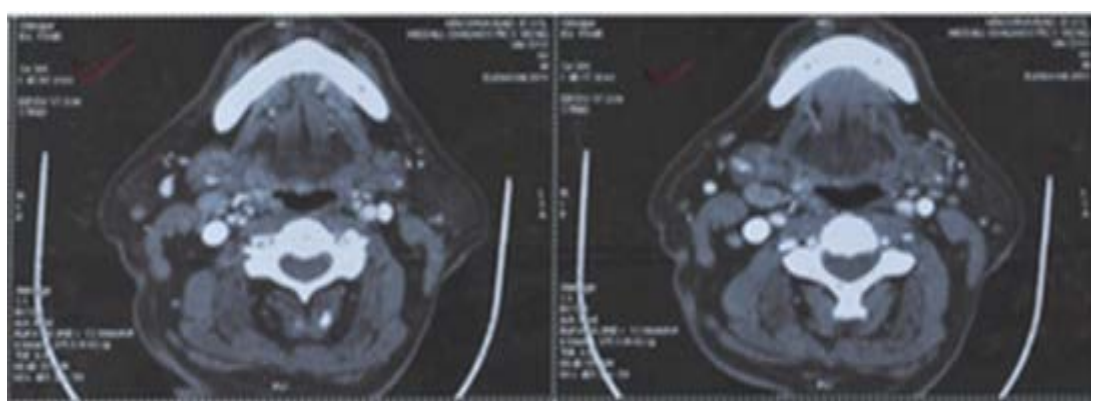

(a)

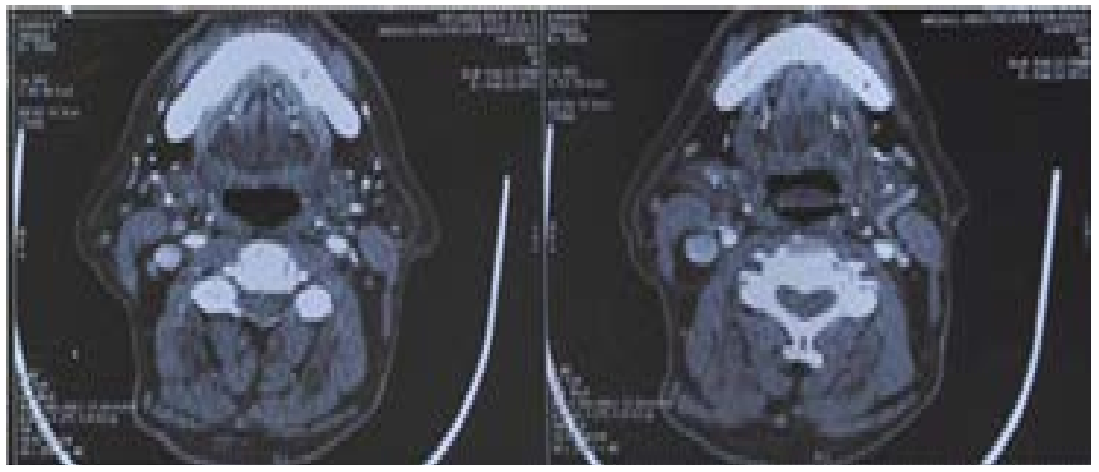

(b)

Figure 3. (a) Pre-treatment CT scan showing a mass measuring $3.6 \mathrm{~cm} \times 2.5 \mathrm{~cm} \times$ $2.0 \mathrm{~cm}$ on the right lateral oropharyngeal wall; (b) Post-treatment CT scan showing reduction in the size of submandibular lymph node to $0.5 \times 0.5 \mathrm{~cm}$.

on oral examination. FNAC (fine needle aspiration cytology) from the neck node was reported as moderately differentiated squamous cell carcinoma. A panendoscopy was done to search for the primary. Even a CT scan failed to pick up the primary disease site. The patient was started on weekly cisplatin $40 \mathrm{mg} / \mathrm{m}^{2}$ and nimotuzumab $200 \mathrm{mg}$ for 6 weekly cycles. Radiation was delivered to a total dose of $66 \mathrm{~Gy} / 33$ fractions $/ 6 \frac{1}{2} 2$ weeks. CT scan done six weeks after the completion of RT showed regression of the nodal mass to $3 \mathrm{~cm} \times 2 \mathrm{~cm}$ (partial response). PET CT was done to see the functional uptake and PET CT showed uptake (Figure 4). A radical neck dissection was performed for the residual node and the histopathological examination of lymph node did 


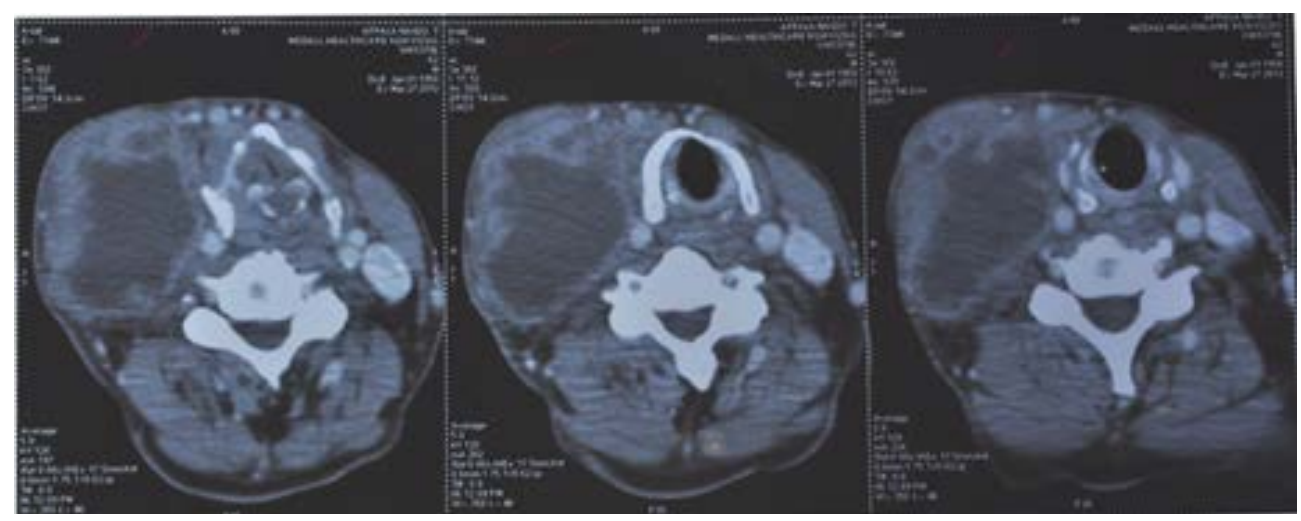

(a)

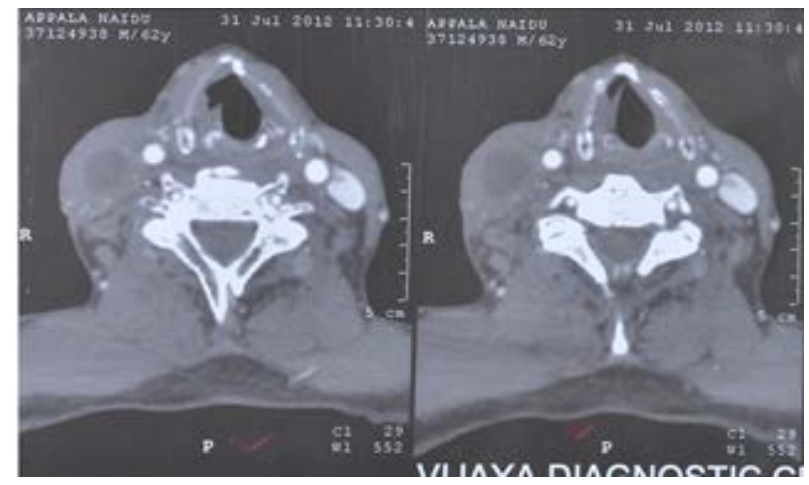

(b)

Figure 4. (a) Pre-treatment CECT of neck showing large neck node measuring $7 \mathrm{~cm} \times 6 \mathrm{~cm}$ with central necrosis; (b) Post treatment CT scan-Follow up CECT shows significant residual disease measuring $3 \mathrm{~cm} \times 2 \mathrm{~cm}$.

not reveal any residual disease. This shows the complete pathological response to treatment. Patient was followed up for 18 months.

\subsection{Case 5}

A 72-year-old gentleman presented with swelling on the right side of neck $(3.5 \mathrm{~cm} \times 1.8 \mathrm{~cm})$ for 3 months duration. Oral examination showed a growth involving the right side of the soft palate and tonsillar region that was firm on palpation and measured $4 \mathrm{~cm} \times 3 \mathrm{~cm}$ approximately. He was diagnosed to have Carcinoma Oropharynx T2N2M0. He received 6 cycles of injection carboplatin $150 \mathrm{mg}$ (in view of high creatinine levels of $1.9 \mathrm{mg}$ ) and $200 \mathrm{mg}$ of nimotuzumab along with radiotherapy delivered by IMRT technique to a dose of $6600 \mathrm{cGy} / 33 \mathrm{frac}-$ tions/61/2 weeks. A follow-up PET scan done after the completion of treatment showed complete regression of primary and nodal disease (Figure 5).

\subsection{Case 6}

A 73-year-old male patient presented with proliferative growth measuring $4 \mathrm{~cm} \times 3 \mathrm{~cm}$ involving the lateral and under surface of anterior 2/3rd tongue with extension on to the floor of mouth. Biopsy of the lesion was moderately differentiated squamous cell carcinoma of tongue. The patient had right submandibular node enlarged and measured $2.5 \mathrm{~cm} \times 2 \mathrm{~cm}$. Patient was planned for weekly carboplatin $150 \mathrm{mg}$ in view of poor general condition and nimotuzumab $200 \mathrm{mg}$ weekly for 6weeks. Patient received radiation dose of 6600 cGy/33 fractions for 61ㄴ2 weeks by IMRT protocol. Patient had responded well to treatment (Figure 6).

The demographic characteristics of patients treated with nimotuzumab and chemoradiation in locally advanced head and neck cancers was depicted in Table 1 and the response to treatment (RECIST-Response Evaluation Criteria for Solid Tumors) was shown in Table 2 respectively. 


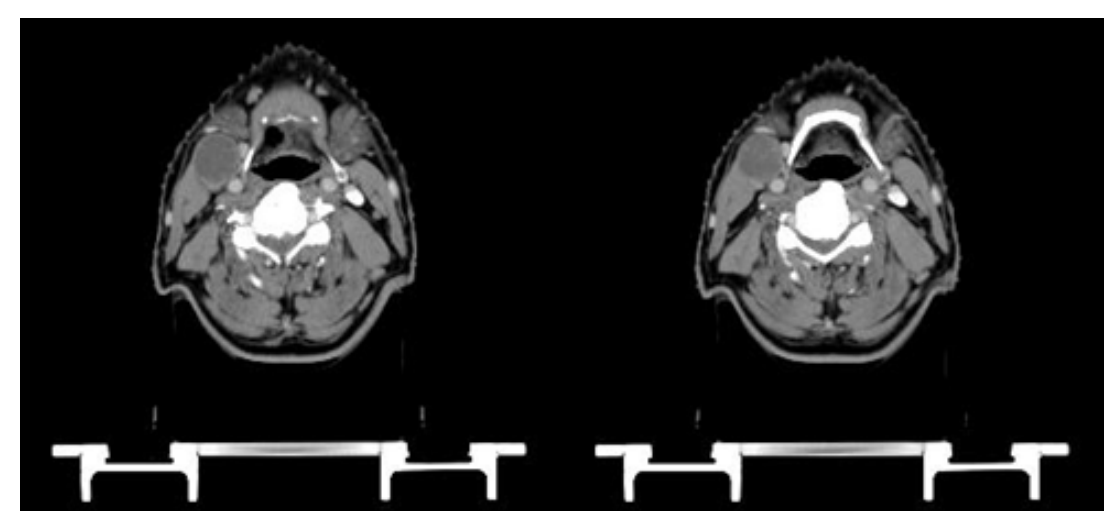

(a)

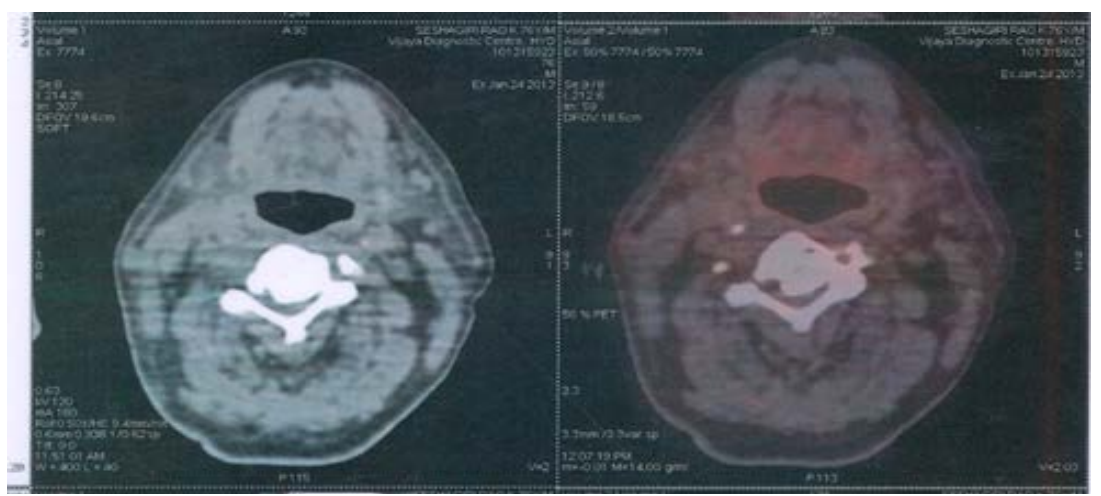

(b)

Figure 5. (a) Pretreatment PET CT scan showing $4 \mathrm{~cm} \times 3 \mathrm{~cm}$ mass in the right soft palate and the tonsillar region; (b) Post treatment PET-CT scan showing complete regression of primary and nodal disease.

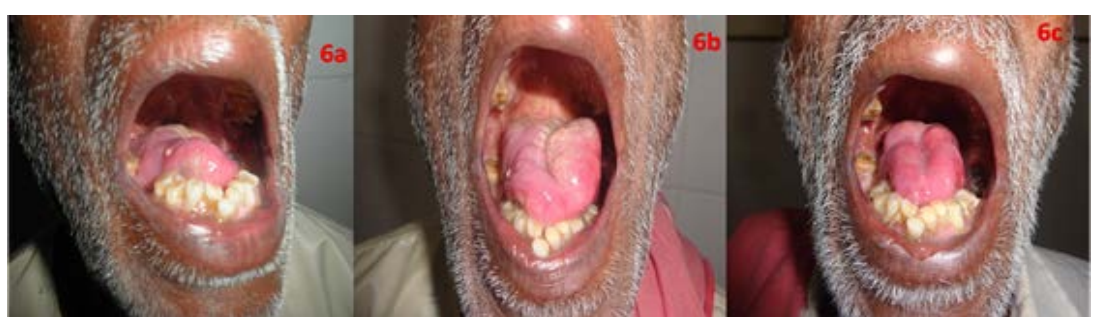

Figure 6. (6a), (6b) and (6c): $2^{\text {nd }}$ week, $3^{\text {rd }}$ week and $4^{\text {th }}$ week of treatment respectively showing tumour regression.

Table 1. Demographic characteristics of patients treated with nimotuzumab and chemoradiation in locally advanced head and neck cancers.

\begin{tabular}{cccccc}
\hline Case No. & Age & Gender & Site & Histopathology & TNM/Stage \\
\hline 1 & 54 & Male & Supraglottis & SCC Grade 2 & T3N2aM0/IVA \\
2 & 50 & Male & Oropharynx & SCC Grade 2 & T4aN2bM0/IVA \\
3 & 68 & Male & Oropharynx & SCC Grade 3 & T2N2bM0/IVA \\
4 & 62 & Male & Unknown & SCC Grade 2 & TxN3M0/IVB \\
5 & 72 & Male & Oropharynx & SCC Grade 2 & T2N1M0/III \\
6 & 73 & Male & Tongue & SCC Grade 2 & T2N1M0/ \\
\hline
\end{tabular}


Table 2. Response to treatment (RECIST—Response Evaluation Criteria for Solid Tumors) [7].

\begin{tabular}{|c|c|c|c|c|}
\hline \multirow{2}{*}{ Patient No. } & \multicolumn{2}{|c|}{ Pretreatment size } & \multicolumn{2}{|c|}{ Post-treatment size } \\
\hline & Primary & Secondary & Primary & Secondary \\
\hline 1 & $4 \mathrm{~cm} \times 3 \mathrm{~cm}$ & $\begin{array}{c}5 \mathrm{~cm} \times 4 \mathrm{~cm} \\
\text { (Right cervical region) }\end{array}$ & No residual disease & $1 \mathrm{~cm} \times 1.5 \mathrm{~cm} \mathrm{PR}$ \\
\hline 2 & Growth size & $\begin{array}{c}5 \times 4 \times 3 \mathrm{~cm} \\
\text { (Right upper cervical region) } \\
\quad 4 \times 2 \mathrm{~cm} \\
\text { (Right submandibular region) }\end{array}$ & No residual disease & No residual disease \\
\hline 3 & $3.6 \mathrm{~cm} \times 2.5 \mathrm{~cm} \times 2 \mathrm{~cm}$ & $\begin{array}{c}2.5 \times 1.2 \mathrm{~cm} \\
\text { (Sub-mandibular region) }\end{array}$ & CR (No residual discharge) & $0.5 \times 0.5 \mathrm{~cm}(\mathrm{CR})$ \\
\hline 4 & Unknown primary & $\begin{array}{l}\quad 7 \times 6 \mathrm{~cm} \\
\text { Right side of neck }\end{array}$ & - & $3 \times 2 \mathrm{~cm}(\mathrm{PR})$ \\
\hline 5 & $4 \times 3 \mathrm{~cm}$ & $\begin{array}{c}3.5 \times 1.8 \mathrm{~cm} \\
\text { (Right cervical region) }\end{array}$ & CR (complete regression) & CR (complete regression) \\
\hline 6 & $4 \times 3 \mathrm{~cm}$ & $\begin{array}{c}2.5 \times 2 \mathrm{~cm} \\
\text { (Right submandibular lobe) }\end{array}$ & - & - \\
\hline
\end{tabular}

\section{Discussion}

EGFR overexpression is present in about $80 \%$ - 100\% of head and neck squamous cell carcinomas [8] and has been linked to radio and chemotherapy resistance resulting in poor treatment outcomes [9]. The potential treatment benefit from inhibiting this receptor has seen aggressive endeavors in the research and the development of therapeutic drugs targeting these receptors. Nimotuzumab, also known as h-R3, is an anti-EGFR monoclonal antibody having anti-angiogenic, anti-apoptotic and anti-proliferative activity [10]. In all the clinical trials so far, it is not associated with any severe cutaneous toxicity as compared to the widely popular cetuximab that is notorious for typical acneform rash affecting $38 \%$ of patients thereby impairing the quality of life [10].

A study by the Sendo foundation discovered that a weekly dose of $200 \mathrm{mg}$ nimotuzumab as the optimum where one out of five patients had CR and rest had PR [11]. In another study by Crombet et al., the overall survival was seen to increase to 44.3 months at higher doses of $200 \mathrm{mg}$ and $400 \mathrm{mg}$ of nimotuzumab [12]. These findings are echoed in the 6 cases, where three out of six cases show CR and rest PR. Survival in one patient was over 60 months and was in concordance with the phase II clinical trial. This case study restates the long term clinical benefits of nimotuzumab along with CT + RT in the management of locally advanced head and neck cancers.

Radiological CR after therapy is associated with increased survival in advanced head and neck cancer patients [13]. Post treatment CT images of the 2nd patient showed PR, the patient maintained good health and quality of life for over 5 years. The addition of nimotuzumab was well-tolerated by the patient and resulted in survival benefit. It has been seen that in patients achieving PR with nimotuzumab, the disease became surgically resectable [12]. In patient 1, the lymph node achieved PR after treatment and a functional neck dissection was performed subsequently which showed CR.

In a 4-arm study by Reddy et al. that included nimotuzumab, cisplatin and radiotherapy, 100\% SCCHN patients showed response of which $90 \%$ was CR and $10 \%$ was PR. Post treatment survival rate increased to $69.5 \%$ with the addition of nimotuzumab [10]. Similar results were obtained in another study by Babu et al. the addition of nimotuzumab to chemoradiotherapy showed a four-year survival rate (intent-to-treat analysis) of $47 \%$ as compared to $21 \%$ in chemoradiation only arm [14]. In the present series all cases are on follow-up and have shown good local response rates together with progression-free survival on addition of nimotuzumab to chemoradiotherapy.

The standard radiation dose in SCCHN for conventional fractionation RT is 70 Gy that leads to frequent occurrence of Grade 3 or 4 skin and mucous membrane toxicities [15]. The resultant effect is very distressing for the already distressed patient. The introduction of concurrent chemotherapy and nimotuzumab has helped in decreasing the total radiation dose for conventional fractionation to $60 \mathrm{~Gy}-66 \mathrm{~Gy}$ without affecting the survival benefit [16]. This has resulted in skin and mucous membrane toxicities being limited to grade 1 or 2 that are eas- 
ily manageable and tolerated by the patients. Amongst the cases under study, patients 1 and 2 received RT dose of 60 Gy whereas patients 3, 4, 5 and 6 received 66 Gy each. There is no significant toxicity observed in all the patients except for patient 2 who developed xerostomia during the treatment and was treated successfully with amifostine [17] [18].

\section{Conclusion}

Nimotuzumab with its efficacy and improved toxicity profile is beneficial in combination with chemoradiation for locally advanced head and neck cancers in terms of excellent local response rates and progression-free survival. It will be worth exploring its benefits in large prospective study.

\section{References}

[1] Ferlay, J., Shin, H.R., Bray, F., Forman, D., Mathers, C. and Parkin, D.M. (2010) Estimates of Worldwide Burden of Cancer in 2008: GLOBOCAN 2008. International Journal of Cancer, 127, 2893-2917.

http://dx.doi.org/10.1002/ijc.25516

[2] Brockstein, B.E. (2011) Management of Recurrent Head and Neck Cancer: Recent Progress and Future Directions. Drugs, 71, 1551-1559. http://dx.doi.org/10.2165/11592540-000000000-00000

[3] Koness, R.J., Glicksman, A., Liu, L., Coachman, N., Landman, C., Slotman, G., et al. (1997) Recurrence Patterns with Concurrent Platinum-Based Chemotherapy and Accelerated Hyperfractionated Radiotherapy in Stage III and IV Head and Neck Cancer Patients. The American Journal of Surgery, 174, 532-535. http://dx.doi.org/10.1016/S0002-9610(97)81724-2

[4] Brockstein, B., Haraf, D.J., Rademaker, A.W., Kies, M.S., Stenson, K.M., Rosen, F.B., et al. (2004) Patterns of Failure, Prognostic Factors and Survival in Locoregionally Advanced Head and Neck Cancer Treated with Concomitant Chemoradiotherapy: A 9-Year, 337-Patient, Multi- Institutional Experience. Annals of Oncology, 15, 1179-1186. http://dx.doi.org/10.1093/annonc/mdh308

[5] Hama, T., Yuza, Y., Saito, Y., O-uchi, J., Kondo, S., Okabe, M., et al. (2009) Prognostic Significance of Epidermal Growth Factor Receptor Phosphorylation and Mutation in Head and Neck Squamous Cell Carcinoma. The Oncologist, 14, 900-908. http://dx.doi.org/10.1634/theoncologist.2009-0058

[6] Russell, J.S. and Colevas, A.D. (2012) The Use of Epidermal Growth Factor Receptor Monoclonal Antibodies in Squamous Cell Carcinoma of the Head and Neck. Chemotherapy Research and Practice, 2012, Article ID: 761518. http://dx.doi.org/10.1155/2012/761518

[7] Duffaud, F. and Therasse, P. (2000) New Guidelines to Evaluate the Response to Treatment in solid Tumors. Bulletindu Cancer, 87, 881-886.

[8] Kassis, J., Lauffenburger, D.A., Turner, T. and Wells, A. (2001) Tumor Invasion as Dysregulated Cell Motility. Seminarsin Cancer Biology, 11, 105-119. http://dx.doi.org/10.1006/scbi.2000.0362

[9] Akashi, Y., Okamoto, I., Iwasa, T., Yoshida, T., Suzuki, M., Hatashita, E., et al. (2008) Enhancement of the Antitumor Activity of Ionizing Radiation by Nimotuzumab, a Humanized Monoclonal Antibody to the Epidermal Growth Factor Receptor, in Non-Small Cell Lung Cancer Cell Lines of Differing Epidermal Growth Factor Receptor Status. British Journal of Cancer, 98,749-755. http://dx.doi.org/10.1038/sj.bjc.6604222

[10] Boland, W.K. and Bebb, G. (2009) Nimotuzumab: A Novel Anti-EGFR Monoclonal Antibody That Retains Anti-EGFR Activity While Minimizing Skin Toxicity. Expert Opinion on Biological Therapy, 9, 1199-1206. http://dx.doi.org/10.1517/14712590903110709

[11] Rojo, F., Gracias, E., Villena, N., Cruz, T., Corominas, J.M., Corradino, I., et al. (2010) Pharmacodynamic Trial of Nimotuzumab in Unresectable Squamous Cell Carcinoma of the Head and Neck: A SENDO Foundation Study. Clinical Cancer Research, 16, 2474-2482. http://dx.doi.org/10.1158/1078-0432.CCR-09-3042

[12] Crombet, T., Osorio, M., Cruz, T., Roca, C., del Castillo, R., Mon, R., et al. (2004) Use of the Humanized Anti-Epidermal Growth Factor Receptor Monoclonal Antibody h-R3 in Combination with Radiotherapy in the Treatment of Locally Advanced Head and Neck Cancer Patients. Journal of Clinical Oncology, 22, 1646-1654. http://dx.doi.org/10.1200/JCO.2004.03.089

[13] Fountzilas, G., Kosmidis, P., Avramidis, V., Nikolaou, A., Kalogera-Fountzila, A., Makrantonakis, P., et al. (1997) LongTerm Survival Data and Prognostic Factors of a Complete Response to Chemotherapy in Patients with Head and Neck Cancer Treated with Platinum-Based Induction Chemotherapy: A Hellenic Cooperative Oncology Group Study. Medical and Pediatric Oncology, 28, 401-410. http://dx.doi.org/10.1002/(SICI)1096-911X(199706)28:6<401::AID-MPO2>3.3.CO;2-0

[14] Babu, K.G., Viswanath, L., Reddy, B.K., Shenoy, K., Shenoy, A., Naveen, T., et al. (2010) An Open-Label, Rando- 
mized, Study of h-R3mAb (Nimotuzumab) in Patients with Advanced (Stage III or IVa) Squamous Cell Carcinoma of Head and Neck (SCCHN): Four-Year Survival Results from a Phase IIb Study. Journal of Clinical Oncology, 28, $15 S$.

[15] Fletcher, G.H. (1980) Textbook of Radiotherapy. 3rd Edition, Lea and Febiger, Philadelphia.

[16] Rodriguez, M.O., Rivero, T.C., del Castillo Bahi, R., Muchuli, C.R., Bilbao, M.A., Vinageras, E.N., et al. (2010) Nimotuzumab plus Radiotherapy for Unresectable Squamous-Cell Carcinoma of the Head and Neck. Cancer Biology and Therapy, 9, 343-349. http://dx.doi.org/10.4161/cbt.9.5.10981

[17] Brizel, D.M., Wasserman, T.H., Henke, M., Strnad, V., Rudat, V., Monnier, A., et al. (2000) Phase III Randomized Trial of Amifostine as a Radioprotector in Head and Neck Cancer. Journal of Clinical Oncology, 18, 3339-3345.

[18] Koukourakis, M.I., Kyrias, G., Kakolyris, S., Kouroussis, C., Frangiadaki, C., Giatromanolaki, A., et al. (2000) Subcutaneous Administration of Amifostine during Fractionated Radiotherapy: A Randomized Phase II Study. Journal of Clinical Oncology, 18, 2226-2233. 